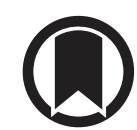

CrossMark

\title{
The effects of parenteral prostacyclin therapy as add-on treatment to oral compounds in Eisenmenger syndrome
}

\begin{abstract}
To the Editor:
Pulmonary arterial hypertension (PAH) develops in $5-10 \%$ of patients with congenital heart disease (CHD) [1], and PAH associated with congenital heart disease (PAH-CHD) accounts for a significant proportion of PAH cases (34-42\%) [2]. Eisenmenger syndrome is at the extreme end of the spectrum of PAH-CHD, with an untreated 10-year mortality rate of 30-40\% [3]. Despite decreasing incidence in developed countries [4], Eisenmenger syndrome is likely to remain a common complication of CHD in low- to middle-income countries [5]. The emergence of PAH therapies has significantly altered the management of Eisenmenger syndrome, with evidence of an improvement in clinical status, exercise tolerance and haemodynamics [6, 7]. Oral combination therapy and intravenous epoprostenol, both well established in the treatment of idiopathic PAH, have been used successfully in Eisenmenger syndrome to further improve outcomes $[8,9]$. However, studies evaluating the safety and efficacy of "triple combination" therapy in Eisenmenger syndrome remain scarce, being limited to small patient cohorts or lacking information on invasive haemodynamics [10-12]. Furthermore, concerns regarding the safety of long-term i.v. therapy and indwelling central venous catheters in patients with pulmonary-to-systemic shunts may have contributed to the slow uptake of prostanoid therapy in this cohort. Nonetheless, there is an early signal of benefit of combination therapy with prostanoids in Eisenmenger syndrome requiring further investigation. We sought to evaluate the use of add-on parenteral prostanoids after failure of dual oral combination therapy in a contemporary cohort of Eisenmenger syndrome patients.
\end{abstract}

This retrospective, longitudinal, cohort study recruited patients with Eisenmenger syndrome under active follow-up in three European tertiary centres between January 2012 and October 2018. All patients were on baseline therapy with both a phosphodiesterase- 5 inhibitor and an endothelin receptor antagonist. Patients were considered for prostanoid therapy following an inadequate clinical or haemodynamic response to combination therapy or disease progression after a period of stability. Other forms of PAH-CHD were excluded. For each patient, clinical and haemodynamic variables were collected prior to initiation of prostanoid therapy and at the last available follow-up. Survival status was assessed to April 2019. Data are presented as $\mathrm{n}(\%)$, median (range), or mean \pm SD.

A total of 28 patients were included (average age $38 \pm 14$ years, $21 \%$ male). The majority of patients had a post-tricuspid shunt (68\%). The most common defect was a ventricular septal defect in 13 (46\%) patients, followed by an atrial septal defect in 29\% (63\% secundum, 25\% primum, $13 \%$ sinus venosus). Average resting saturations were $82 \pm 6 \%$, with the vast majority (96\%) exhibiting resting saturations $<90 \%$ on air. The majority of patients (89\%) were in New York Heart Association functional class $3(78 \%)$ or $4(21 \%)$. Average 6-min walk distance $(6 \mathrm{MWD})$ was low $(233 \pm 140 \mathrm{~m})$, and $39 \%$ walked $<200 \mathrm{~m}$. Serum N-terminal pro-brain natriuretic peptide (NT-proBNP) concentration was also significantly raised with a median concentration of 3087 (234-7428) $\mathrm{pg} \cdot \mathrm{mL}^{-1}$ (normal $<125 \mathrm{pg} \cdot \mathrm{mL}^{-1}$ ). Baseline haemodynamics confirmed severe precapillary pulmonary hypertension: pulmonary vascular resistance (PVR) 20.7 \pm 9.6 Wood units (WU), 86\% with PVR $>10 \mathrm{WU}$, and $\mathrm{Q}_{\mathrm{p}} / \mathrm{Q}_{\mathrm{s}} 1.0 \pm 0.1$ (bidirectional shunting). Systemic cardiac output $\left(\mathrm{Q}_{\mathrm{s}}\right)$ was reduced $\left(3.2 \pm 0.9 \mathrm{~L} \cdot \mathrm{min}^{-1}\right)$, with $57 \%$ having a systemic cardiac index $\left(\mathrm{Q}_{\mathrm{si}}\right)<2.0 \mathrm{~L} \cdot \mathrm{min}^{-1} \cdot \mathrm{m}^{-2}$.

@ERSpublications

In this European cohort of Eisenmenger patients, prostanoid therapy, as part of triple combination therapy, was found to be safe and effective in improving exercise capacity, natriuretic peptide levels and haemodynamic parameters over a 2-year period http://bit.ly/2Zl3W1Z

Cite this article as: D'Alto $\mathrm{M}$, Constantine $\mathrm{A}$, Balint $\mathrm{OH}$, et al. The effects of parenteral prostacyclin therapy as add-on treatment to oral compounds in Eisenmenger syndrome. Eur Respir J 2019; 54: 1901401 [https://doi.org/10.1183/13993003.01401-2019]. 
The vast majority of patients $(26,92.9 \%)$ received subcutaneous treprostinil and the remainder intravenous epoprostenol. The median doses of treprostinil and epoprostenol at the end of uptitration were 40 (22-65) $\mathrm{ng} \cdot \mathrm{kg}^{-1} \cdot \mathrm{min}^{-1}$ and $33(32-34) \mathrm{ng} \cdot \mathrm{kg}^{-1} \cdot \mathrm{min}^{-1}$, respectively. At a median follow-up of 27 (2-65) months (repeat cardiac catheterisation in 57\%), there was no drop in saturations $(82 \pm 6 \%$ versus $82 \pm 4 \%$ ) or resting blood pressure, but a significant increase in 6MWD (mean $272 \pm 109$ versus $365 \pm 113 \mathrm{~m}$, p=0.0003; figure 1a). World Health Organization (WHO) functional class improved in $64 \%$, remained unchanged in eight $(29 \%)$ and deteriorated in two $(7 \%)$ patients $(\mathrm{p}=0.002)$. A reduction in NT-proBNP levels was observed (median 3087 (234-7428) versus 1126 (123-5882) $\mathrm{pg} \cdot \mathrm{mL}^{-1}, \mathrm{p}<0.0001$; figure 1b). Using the cut-offs proposed by the European Society of Cardiology (ESC)/European Respiratory Society (ERS) guideline risk assessment tool for PAH patients [13], the following variables improved: WHO functional class in $64 \%$, $6 \mathrm{MWD}$ in $25 \%$ and NT-proBNP level in $32 \%$. Patients who moved into a lower risk category in at least two parameters were more likely to have a post-tricuspid defect $(\mathrm{p}=0.04)$ and a lower $6 \mathrm{MWD}(216 \pm 75.2$ versus $312 \pm 115 \mathrm{~m}, \mathrm{p}=0.03$ ). Treatment resulted in $18 \%$ of patients moving into the low-risk category with respect to at least two parameters, whereas none improved to the low-risk group with respect to these three parameters.

On follow-up cardiac catheterisation, significant reductions in mean pulmonary artery pressure $(72 \pm 17$ versus $68 \pm 12 \mathrm{mmHg}, \mathrm{p}=0.005)$ and $\mathrm{PVR}(21 \pm 10$ versus $17 \pm 7 \mathrm{WU}, \mathrm{p}=0.008$; figure $1 \mathrm{c})$ were accompanied by an improvement in cardiac index $\left(2.0 \pm 0.5\right.$ versus $2.3 \pm 0.3 \mathrm{~L} \cdot \mathrm{min}^{-1} \cdot \mathrm{m}^{-2}, \mathrm{p}=0.005$; figure $\left.1 \mathrm{~d}\right)$ and a reduction in right atrial pressure compared to baseline $(11 \pm 5$ versus $8 \pm 2 \mathrm{mmHg}, \mathrm{p}=0.01)$. Finally, there was a small increase in the fraction of pulmonary-to-systemic shunting $\left(\mathrm{Q}_{\mathrm{p}} / \mathrm{Q}_{\mathrm{s}} 1 \pm 0.1\right.$ versus $1.1 \pm 0.1$,
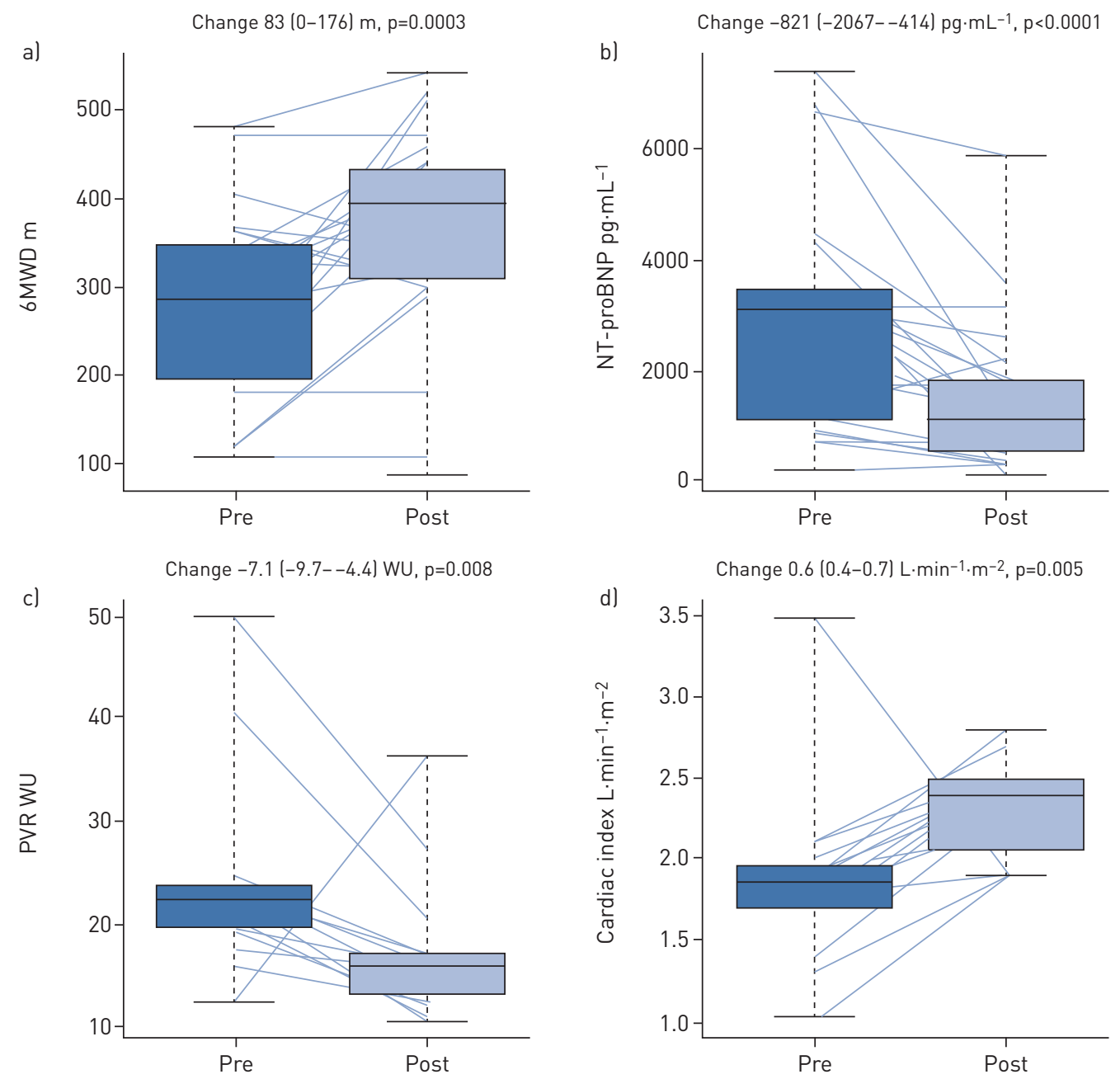

FIGURE 1 Effect of prostanoid therapy on a) 6-min walk distance (6MWD); b) N-terminal pro-brain natriuretic peptide (NT-proBNP) level; c) pulmonary vascular resistance (PVR); and d) cardiac index. Data are presented as median, 25th and 75th percentiles and range. The change with therapy in each patient is shown as light grey connecting lines. WU: Wood units. 
$\mathrm{p}=0.03$ ). Survival following prostanoid initiation was $92 \%$ and $80 \%$ at 1 and 2 years, respectively. During follow-up, six (21\%) patients died, three (11\%) patients were listed for lung transplantation and one (4\%) underwent lung transplantation. No patients discontinued treatment during the study period.

In this study, parenteral prostanoid therapy was safe with no instances of discontinuation of therapy. Third-line therapy in this Eisenmenger syndrome cohort was associated with an improvement in exercise capacity, natriuretic peptide levels and haemodynamics. Early escalation to combination PAH therapy is fundamental to the modern management of idiopathic (IPAH) and connective tissue disease-related PAH (CTD-PAH). While PAH-CHD is as common as IPAH and CTD-PAH, there is still limited evidence on the efficacy of combination therapy. It is likely that prostanoids are introduced late in many Eisenmenger syndrome patients, even though assessing functional limitation through symptoms can be difficult in this cohort. Our study strongly supports the value of escalation of PAH therapies in Eisenmenger syndrome, moving patients towards a lower risk profile.

The ESC/ERS pulmonary hypertension guidelines provide a risk assessment tool for IPAH using published prognostic variables, which may apply to other forms of $\mathrm{PAH}$; the goal of $\mathrm{PAH}$ therapy is to move patients towards the low-risk group and improve their survival. In our study, the addition of parenteral treatment was associated with a significant improvement in clinical parameters, suggesting that Eisenmenger syndrome patients on oral combination therapy can be further optimised. This was especially true for patients with post-tricuspid shunts and those with a lower 6MWD, supporting escalation in those who have not responded sufficiently to combination therapy. Despite significant improvement in multiple variables, few patients improved to a low-risk status with respect to all three parameters from the ESC/ERS guideline risk assessment tool assessed in our study. A minority of patients achieving a low-risk profile is in line with other studies evaluating add-on prostanoid therapy in other cohorts, consisting mostly of patients with IPAH [14, 15]. However, Eisenmenger syndrome patients differ significantly from other types of PAH in terms of pathophysiology and prognosis [16], and a risk score accounting for the unique features of Eisenmenger syndrome is urgently needed. Eisenmenger patients who are candidates for third-line PAH therapy remain at significant risk of death and should be considered for heart-lung or lung transplantation with repair of the cardiac defect. Early referral for assessment is key in maximising suitability for transplantation, before the development of multiorgan failure. In our cohort, only one patient underwent lung transplantation with CHD repair. Given the decline in heart-lung transplantation, in conjunction with the continued expansion of the CHD population [17], achieving stability on PAH therapies, via timely stepwise escalation, is essential [7].

The limitations of this study include its retrospective design, limited numbers of patients with a rare condition, the availability of repeat cardiac catheterisation in only a subset of patients reflecting differing clinical practices between centres, and the lack of a comparison group. The time from initiation of therapy to follow-up was not predefined and varied between patients. The low event rate during follow-up meant that we were unable to perform any meaningful survival analysis in this population.

In conclusion, this study has demonstrated that the addition of a parenteral prostanoid in Eisenmenger syndrome patients on dual oral combination therapy is safe with no patients needing to interrupt therapy due to side-effects at 2 years of follow-up, resulting in a significant improvement in clinical and haemodynamic variables. Further trials are needed to define the optimal strategy for treatment escalation in Eisenmenger syndrome patients, and the role of alternative modes of delivery (e.g. implantable pumps).

Michele D'Alto $\oplus^{1}$, Andrew Constantine $\oplus^{2}$, Olga Hajnalka Balint ${ }^{3}$, Emanuele Romeo ${ }^{1}$, Paola Argiento ${ }^{1}$, Laszlo Ablonczy ${ }^{3}$, Nika Skoro-Sajer ${ }^{4}$, George Giannakoulas ${ }^{5}$ and Konstantinos Dimopoulos ${ }^{2}$

${ }^{1}$ Dept of Cardiology, University "L. Vanvitelli" - Monaldi Hospital, Naples, Italy. ${ }^{2}$ Adult Congenital Heart Centre and National Centre for Pulmonary Hypertension, Royal Brompton Hospital, London, UK. ${ }^{3}$ György Gottsegen Hungarian Institute of Cardiology, Budapest, Hungary. ${ }^{4}$ Dept of Internal Medicine II, Division of Cardiology, Medical University of Vienna, Vienna, Austria. ${ }^{5}$ Dept of Cardiology, AHEPA University Hospital, Aristotle University of Thessaloniki, Thessaloniki, Greece.

Correspondence: Konstantinos Dimopoulos, Adult Congenital Heart Centre, Royal Brompton and Harefield NHS Foundation Trust, Sydney Street, SW3 6NP London, UK. E-mail: k.dimopoulos02@gmail.com

Received: 02 July 2019 | Accepted after revision: 26 July 2019

Conflict of interest: M. D'Alto reports grants and personal fees from Actelion, Pfizer, GlaxoSmithKline, Dompè and Bayer/MSD, outside the submitted work. A. Constantine reports grants from Actelion, outside the submitted work. O.H. Balint reports personal fees from Actelion, Lilly, AOP Orphan and Bayer/MSD, outside the submitted work. E. Romeo reports grants and personal fees from GlaxoSmithKline, Dompè and MSD, outside the submitted work. P. Argiento reports grants and personal fees from GlaxoSmithKline, Dompè and MSD, outside the submitted work. L. Ablonczy has nothing to disclose. N. Skoro-Sajer reports grants and personal fees from AOPOrphan Pharmaceuticals, Actelion, Bayer, GlaxoSmithKline, Pfizer and United Therapeutics, outside the submitted work. G. Giannakoulas reports grants and personal fees from Actelion, United Therapeutics, Pfizer, GlaxoSmithKline, Bayer/MSD and Lilly, outside the submitted 
work. K. Dimopoulos reports grants, personal fees and non-financial support from Actelion, personal fees from Pfizer,

GlaxoSmithKline and Bayer/MSD, outside the submitted work.

\section{References}

1 van Riel ACMJ, Schuuring MJ, van Hessen ID, et al. Contemporary prevalence of pulmonary arterial hypertension in adult congenital heart disease following the updated clinical classification. Int J Cardiol 2014; 174: 299-305.

2 van der Velde ET, Vriend JWJ, Mannens MM, et al. CONCOR, an initiative towards a national registry and DNA-bank of patients with congenital heart disease in the Netherlands: rationale, design, and first results. Eur J Epidemiol 2005; 20: 549-557.

3 Diller GP, Kempny A, Inuzuka R, et al. Survival prospects of treatment naïve patients with Eisenmenger: a systematic review of the literature and report of own experience. Heart 2014; 100: 1366-1372.

4 Hjortshøj CS, Jensen AS, Sørensen K, et al. Epidemiological changes in Eisenmenger syndrome in the Nordic region in 1977-2012. Heart 2017; 103: 1353-1358.

5 Kempny A, Dimopoulos K, Gatzoulis MA. Declining incidence and prevalence of Eisenmenger syndrome in the developed world: a triumph of modern medicine. Heart 2017; 103: 1313-1314.

6 Galiè N, Beghetti M, Gatzoulis MA, et al. Bosentan therapy in patients with Eisenmenger syndrome: a multicenter, double-blind, randomized, placebo-controlled study. Circulation 2006; 114: 48-54.

7 Dimopoulos $\mathrm{K}$, Inuzuka R, Goletto S, et al. Improved survival among patients with Eisenmenger syndrome receiving advanced therapy for pulmonary arterial hypertension. Circulation 2010; 121: 20-25.

8 Rosenzweig EB, Kerstein D, Barst RJ. Long-term prostacyclin for pulmonary hypertension with associated congenital heart defects. Circulation 1999; 99: 1858-1865.

9 D'Alto M, Romeo E, Argiento P, et al. Bosentan-sildenafil association in patients with congenital heart disease-related pulmonary arterial hypertension and Eisenmenger physiology. Int J Cardiol 2012; 155: 378-382.

10 Thomas IC, Glassner-Kolmin C, Gomberg-Maitland M. Long-term effects of continuous prostacyclin therapy in adults with pulmonary hypertension associated with congenital heart disease. Int J Cardiol 2013; 168: 4117-4121.

11 Hascoet S, Fournier E, Jaiis X, et al. Outcome of adults with Eisenmenger syndrome treated with drugs specific to pulmonary arterial hypertension: a French multicentre study. Arch Cardiovasc Dis 2017; 110: 303-316.

12 Skoro-Sajer N, Gerges C, Balint OH, et al. Subcutaneous treprostinil in congenital heart disease-related pulmonary arterial hypertension. Heart 2018; 104: 1195-1199.

13 Galiè N, Humbert M, Vachiery J-L, et al. 2015 ESC/ERS Guidelines for the diagnosis and treatment of pulmonary hypertension: The Joint Task Force for the Diagnosis and Treatment of Pulmonary Hypertension of the European Society of Cardiology (ESC) and the European Respiratory Society (ERS). Eur Respir J 2015; 46: 903-975.

14 Bartolome SD, Sood N, Shah TG, et al. Mortality in patients with pulmonary arterial hypertension treated with continuous prostanoids. Chest 2018; 154: 532-540.

15 Olsson KM, Richter MJ, Kamp JC, et al. Intravenous treprostinil as an add-on therapy in patients with pulmonary arterial hypertension. J Heart Lung Transplant 2019; 38: 748-756.

16 Dimopoulos K, Wort SJ, Gatzoulis MA. Pulmonary hypertension related to congenital heart disease: a call for action. Eur Heart J 2014; 35: 691-700.

17 Dimopoulos K, Muthiah K, Alonso-Gonzalez R, et al. Heart or heart-lung transplantation for patients with congenital heart disease in England. Heart 2019; 105: 596-602. 